\title{
Pharmaceutical Development of 5-Fluorouracil- Eluting Stents for the Potential Treatment of Gastrointestinal Cancers and Related Obstructions
}

This article was published in the following Dove Press journal: Drug Design, Development and Therapy

\author{
Mohammad Arafat (D) \\ Yunmei Song $\mathbb{D}^{1}$ \\ Kyle Brewer ${ }^{2}$ \\ Paris Fouladian' \\ Ankit Parikh' \\ Hugo Albrecht ${ }^{3}$ \\ Anton Blencowe ${ }^{2}$ \\ Sanjay Garg (iD)
}

'Pharmaceutical Innovation and Development (PIDG) Group, Clinical and Health Sciences, University of South Australia, Adelaide, SA, 5000, Australia; ${ }^{2}$ Applied Chemistry and Translational Biomaterials (ACTB) Group, Clinical and Health Sciences, University of South Australia, Adelaide, SA, 5000, Australia; ${ }^{3}$ Drug Discovery and Development Group, Clinical and Health Sciences, University of South Australia, Adelaide, SA, 5000, Australia
Correspondence: Sanjay Garg

Pharmaceutical Innovation and

Development (PIDG) Group, Clinical and

Health Sciences, University of South

Australia, Adelaide, SA, 5000, Australia

Email Sanjay.Garg@unisa.edu.au

Anton Blencowe

Applied Chemistry and Translational Biomaterials (ACTB) Group, Clinical and Health Sciences, University of South Australia, Adelaide, SA, 5000, Australia Email Anton.Blencowe@unisa.edu.au
Background: Drug-eluting gastrointestinal (GI) stents are emerging as promising platforms for the treatment of GI cancers and provide the combined advantages of mechanical support to prevent lumen occlusion and as a reservoir for localized drug delivery to tumors. Therefore, in this work we present a detailed quality assurance study of 5-fluorouracil (5FU) drug-eluting stents (DESs) as potential candidates for the treatment of obstructive GI cancers.

Methods: The 5FU DESs were fabricated via a simple two-step sequential dip-coating process of commercial GI self-expanding nitinol stents with a 5FU-loaded polyurethane basecoat and a drug-free protective poly(ethylene-co-vinyl acetate) topcoat. The drug loading, content uniformity and drug stability were determined using a validated high-performance liquid chromatography (HPLC) method, which is also recommended in the United States Pharmacopeia. In vitro drug release studies were performed in phosphate buffered saline to determine the drug releasing properties of the two 5FU-loaded stents. Gas chromatography (GC) and HPLC were employed to determine total residual tetrahydrofuran and $N, N$-dimethylformamide in the stents remaining from the manufacturing process. Sterilization of the stents was performed using gamma radiation and stability testing was carried out for 3 months.

Results: The drug loading analysis revealed excellent uniformity in the distribution of 5FU between and within individual stents. Determination of drug stability in the biorelevant release media confirmed that $5 \mathrm{FU}$ remains stable over $100 \mathrm{~d}$. In vitro drug release studies from the stents revealed sustained release of 5FU across two different time scales (161 and $30 \mathrm{~d}$ ), and mathematical modeling of drug release profiles revealed a diffusion-controlled mechanism for the sustained 5FU release. GC and HPLC analysis revealed that the daily residual solvent leached from the stents was below the United States (US) Food and Drug Administration (FDA) guidelines, and therefore, unlikely to cause localized/systemic toxicities. Sterilization of the stents with gamma radiation and accelerated stability tests over a period of 3 months revealed no significant effect on the stability or in vitro release of 5FU. Conclusion: Our results demonstrate that the 5FU DESs meet relevant quality standards and display favourable drug release characteristics for the potential treatment of GI cancers and related obstructions.

Keywords: drug-eluting stent, 5-fluorouracil, gastrointestinal cancer, self-expanding metal stents

\section{Introduction}

Conventional gastrointestinal (GI) stents have a proven track record of clinical safety and effectiveness in the localized management of stenoses and/or obstructions. ${ }^{1}$ Nevertheless, in-stent restenosis (ISR) is a common problem due to benign hyperplastic or malignant tissue growth within the stented region. ${ }^{1-3}$ ISR 
frequently results in a significant reduction in the effective duration of the stenting treatment, thus necessitating placement of a second stent or emergency surgical intervention. ${ }^{1-4}$ While the introduction of vascular drugeluting stents (DESs) has drastically reduced the incidence of ISR among coronary artery disease (CAD) patients, ${ }^{2,5,6}$ the translation of GI DESs towards the clinic holds promise for the treatment of ISR and simultaneous reduction of tumor burden for GI cancers.

DESs are generally composed of three primary components: drug, polymeric drug-delivery coating/carrier, and the stent platform. ${ }^{3,7,8}$ To date, GI DESs have been investigated using contemporary chemotherapeutics in conjunction with different types of GI stents. ${ }^{9-13}$ These specialised GI stents have been designed to provide controlled and localized delivery of drugs at the stenting site, with the intent of maximising drug bioavailability within the local tumor tissue and minimising systemic toxicities. The selection of an appropriate anticancer drug and dose regime is crucial to ensure the clinical safety and effectiveness of DES-based chemotherapy, similar to that required for conventional systemic and non-systemic chemotherapies. ${ }^{3,14-16}$ While a large number of United States (US) Food and Drug Administration (FDA)approved cancer drugs are widely used for the clinical treatment of GI cancers, ${ }^{14,17}$-fluorouracil (5FU) remains one of the most popular due to its high potency and broad anticancer activity. Commonly, $5 \mathrm{FU}$ is administered intravenously for the treatment of GI cancers as a result of poor oral bioavailability, although this can be associated with severe GI, hematologic, cardiac and dermatologic side effects. ${ }^{14,18-21}$ Few studies have investigated the potential of localized stent-based 5FU delivery to overcome the toxicities associated with systemic delivery. ${ }^{18-20,22-24}$ Several studies have evaluated the efficacy of 5FU-eluting esophageal stents in vivo and revealed significantly higher 5FU concentrations in the local esophageal tissue as compared to peripheral organs without any signs of tissue damage. ${ }^{19,23,24}$ In addition, $\mathrm{Li}$ et al prepared a series of biodegradable, 5FU-loaded polydioxanone stents and demonstrated that higher 5FU loadings correlated with superior anti-ISR and antitumor effects in a mice xenograft model. ${ }^{20}$ These prior studies support the feasibility of stent-based localized anticancer drug delivery with reduced systemic toxicities, and demonstrate that $5 \mathrm{FU}$ is a suitable candidate for drug-eluting GI stents.

Another critical component of DESs is the polymeric coating/carrier which should provide sufficient drug loading capacity ${ }^{8,25}$ and effective control of the drug release kinetics. ${ }^{26}$ To date, various biostable and biodegradable polymers have been investigated in combination with different self-expandable metal stents (SEMSs) for the fabrication of DES platforms. ${ }^{1,27,28}$ However, biostable polymers are preferable for GI DES, as biodegradable polymer coatings could result in early stent blockage due to malignant tumor growth, stricture recurrence, or stent migration. ${ }^{1,27}$ While biostable polyurethanes (PUs), polysiloxanes, and poly(ethylene-co-vinyl acetate) (PEVA) have been commonly used for DES applications, ${ }^{7,27,29}$ PUs offer excellent biocompatibility and mechanical properties, and can readily be combined with drugs. ${ }^{1,27}$ Nevertheless, the high aqueous solubility of $5 \mathrm{FU}$ $(13.26 \mathrm{mg} / \mathrm{mL})^{30}$ can potentially result in burst release profiles, and therefore, it is advantages to incorporate a drug-free protective layer to slow the diffusion and release kinetics of $5 \mathrm{FU}$ from coated stents. ${ }^{31}$

While previous studies have demonstrated the potential of stent-based localized 5FU delivery, there is very little information regarding the critical quality attributes that are essential for any DES platform from a quality control or regulatory perspective. Unfortunately, all available regulatory documents or literature detailing quality control requirements, tests/procedures, and recommendations are based on vascular coronary DESs ${ }^{2,8}$ and there is no such information specifically for non-vascular DESs. In our previous study, we demonstrated the potential advantages of dip-coating to rapidly and reproducibly produce DESs for the controlled delivery of 5FU for the treatment of GI cancers and related obstructions. ${ }^{32}$ Therefore, in the present study we aimed to utilise dip-coating for the fabrication of 5FU-loaded GI stents and assess their performance via a series of quality control checks in order to ensure both their quality and functionality in accordance with current FDA requirements. Here, we report the first comparative evaluation of the critical quality attributes of two 5FU DESs fabricated with the same polymer coating technique and formulation but using two different types of self-expanding nitinol stent platforms.

\section{Materials and Methods Materials}

Clinically relevant, non-vascular self-expanding silicone (Si) membrane-covered (Niti-S ${ }^{\mathrm{TM}}$ S-type biliary stents; diameter $=10 \mathrm{~mm}$ ) and bare (uncovered) nitinol stents (Niti-S ${ }^{\text {TM }}$ D-type pyloric/duodenal/enteral colonic stents; 
diameter $=22 \mathrm{~mm}$ ) were kindly supplied by Taewoong Medical Co., Ltd (Gimpo-si, Gyeonggi-do, South Korea) (Supplementary Information (SI), Figure S1). ChronoFlex $\mathrm{AL}$, a biostable medical-grade aliphatic polycarbonatebased thermoplastic PU, with a Shore hardness of $80 \mathrm{~A}$ was kindly provided by AdvanSource Biomaterials Corporation (Wilmington, MA, USA). Tetrahydrofuran (THF, ACS Reagent grade) was purchased from ChemSupply Pty Ltd (Gillman, SA, Australia). 5FU was purchased from Hangzhou Dayang Chem Co., Ltd. (Hangzhou, Zhejiang, China). N,N-Dimethylformamide (DMF, high-performance liquid chromatography (HPLC) grade), PEVA (vinyl acetate (VA) 40 wt. \%), and ammonium hydroxide (ammonia content 28 to 30\%, ACS Reagent grade) were procured from Sigma-Aldrich Pty Ltd (North Ryde BC, NSW, Australia). Dichloromethane (DCM, HPLC grade) and silver aluminum foil self-sealing zip-lock bags were purchased from Merck KGaA (Darmstadt, Germany) and a local supplier, respectively. More detailed information on the materials used in the present study is provided in SI, Table S1. All reagents were of analytical grade and were used as received unless otherwise stated.

\section{Methods}

\section{Fabrication of 5FU-Loaded GI Stents}

Based on our previous study, ${ }^{32}$ DESs were fabricated via the two-step sequential dip-coating of commercial GI nitinol stents with a 5FU-loaded PU (ChronoFlex AL) basecoat and a drug-free protective PEVA topcoat ( $\underline{\mathrm{SI}}$, Table $\underline{\mathrm{S} 2}$ ). Briefly, two different coating solutions were prepared for the basecoat and topcoat application. Initially, 5FU (3.62 g) was dissolved in DMF (41.20 mL) with sonication (Model 5510E-DTH, Branson Ultrasonics Corporation, Danbury, CT, USA). Separately, ChronoFlex AL (52.50 g) was dissolved in THF $(258.80 \mathrm{~mL})$ with stirring and heating at $60{ }^{\circ} \mathrm{C}$ in a water bath. The temperature of the water bath was reduced to $40{ }^{\circ} \mathrm{C}$ and after $30 \mathrm{~min}$ the $5 \mathrm{FU}$ solution was slowly added dropwise. The resulting solution was sonicated for $1 \mathrm{~h}$, heated at $40^{\circ} \mathrm{C}$ in a water bath and then used immediately to coat two different types of commercially available GI stents (Si-covered and bare

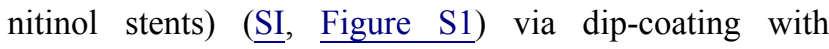
a Model TL0.01 desktop dip-coater (MTI Corporation, Richmond, CA, USA). ${ }^{32}$ The resulting Si-PU $\mathrm{FU}$ and Ba$\mathrm{PU}_{\mathrm{FU}}$ base-coated nitinol stents were dried in an oven for $36 \mathrm{~h}$ at $60{ }^{\circ} \mathrm{C}$, and weighed to determine the mass of the basecoat (after THF/DMF evaporation), which theoretically consisted of $6.5 \% \mathrm{w} / \mathrm{w}$ of $5 \mathrm{FU}$. The drugfree protective topcoat solution was prepared by dissolving PEVA (78 g) in DCM (300 mL) with sonication at $37{ }^{\circ} \mathrm{C}$ for $4 \mathrm{~h}$ and stored at ambient temperature for $>12 \mathrm{~h}$ until further use. The PEVA solution was dip-coated onto the $\mathrm{Si}-\mathrm{PU}_{\mathrm{FU}}$ and $\mathrm{Ba}-\mathrm{PU}_{\mathrm{FU}}$ stents and air-dried for $24 \mathrm{~h}$ in a fume cupboard (Model Dynaflow 1500GRP, Melrose Park, NSW, Australia) to afford Si-PU $\mathrm{FU}_{-P E V A}$ and Ba$\mathrm{PU}_{\mathrm{FU}}$-PEVA stents, which were weighed to determine the mass of the topcoat. A flow chart illustrating the key steps of the DES fabrication process can be found in SI, Figure S2.

\section{HPLC Determination of 5FU}

$5 F U$ was quantified using the reversed-phase HPLC method described in the United States PharmacopeiaNational Formulary (USP-NF). ${ }^{33}$ The detailed HPLC test system configuration and method parameters are summarised in SI, Table S3.

\section{Determination of Drug Loading and Content Uniformity}

Drug content evaluation was performed on the Si-PU $\mathrm{FU}_{\mathrm{H}}$ and $\mathrm{Ba}-\mathrm{PU}_{\mathrm{FU}}$ stents to determine the true amount of $5 \mathrm{FU}$ present in the active PU basecoat layer, as well as the uniformity and distribution of drug within the stent samples. To prepare samples for drug extraction, the Si-PU $\mathrm{FU}_{\mathrm{F}}$ and $\mathrm{Ba}-\mathrm{PU}_{\mathrm{FU}}$ stents were cut into small pieces weighing $14.93 \pm 0.38 \mathrm{mg}$ and $9.85 \pm 0.67 \mathrm{mg}$, respectively $(\mathrm{n}=6$ for both base-coated stent types). The pieces were added separately to DCM $(0.60$ or $0.90 \mathrm{~mL})$ in plastic tubes and the polymer coatings were allowed to completely dissolve over 12 h (SI, Figure S3). Subsequently, $1 \mathrm{~N}$ ammonium hydroxide solution in water $(1.40$ or $2.10 \mathrm{~mL}$ ) was added to each tube, mixed well, and then centrifuged for $15 \mathrm{~min}$ at $3000 \mathrm{rpm}$ and $21^{\circ} \mathrm{C}$. The aqueous phase was collected from each tube and the 5FU was quantified via HPLC.$^{33}$ The efficiency of the extraction process was evaluated using the same procedure, except that known concentrations (range: 584.0 to $2648.0 \mu \mathrm{g} / \mathrm{mL}$ ) of pure $5 \mathrm{FU}$ drug were added to DCM instead of 5FU-loaded stent cut pieces.

\section{FU Stability Studies in Media}

$5 \mathrm{FU}$ stability was assessed in vitro in $10 \mathrm{mM}$ phosphate buffer saline (PBS) at three different $\mathrm{pH}$ values $(5.8,6.6$, and 7.4) over a period of $100 \mathrm{~d}$. Initially, 5FU solutions $(54.57 \pm 0.79 \mu \mathrm{g} / \mathrm{mL})$ were prepared in triplicate in sealed vials and shaken on a horizontal mixer $(20 \mathrm{~mm}$ orbital 
diameter, $175 \mathrm{rpm}$ ) at $37{ }^{\circ} \mathrm{C}$. At specific time intervals, $500 \mu \mathrm{L}$ of the medium was removed from each container and the 5FU concentration was quantified via HPLC. To assess $\mathrm{pH}$ stability or the presence of any drug precipitation, the $\mathrm{pH}$ of solutions was recorded at day 0,1 and 100, followed by microscopic imaging for crystallization using an Olympus BX41TF microscope (Olympus Corporation, Tokyo, Japan).

\section{In vitro Release of 5FU from Coated Stents}

Based on previously reported values for the $\mathrm{pH}$ of the colon (SI, Table S4) and release studies (SI, Table S5), $10 \mathrm{mM}$ PBS at $\mathrm{pH} 7.4$ was selected as a biorelevant medium for studying 5FU release from the coated stents. The full-length Si-PU $\mathrm{FU}-\mathrm{PEVA}$ and $\mathrm{Ba}-\mathrm{PU}_{\mathrm{FU}}-\mathrm{PEVA}$ stents $(\mathrm{n}=3$ for each) were submerged - using a fabric mesh (SI, Figure S4) - in 20 and $40 \mathrm{~mL}$ of medium, respectively, in separate plastic containers, which was sufficient to maintain sink conditions; the saturation concentration of $5 \mathrm{FU}$ in PBS (10 mM, pH 7.4) was determined to be $7.65 \pm$ $1.50 \mathrm{mg} / \mathrm{mL}(\mathrm{n}=4)$. The containers were sealed and placed on a horizontal shaker $(20 \mathrm{~mm}$ orbital diameter, $175 \mathrm{rpm}$ ) at $37{ }^{\circ} \mathrm{C}$. At specific time intervals, $1 \mathrm{~mL}$ of the release medium was withdrawn from each container for 5FU quantification via HPLC and replaced with $1 \mathrm{~mL}$ of fresh PBS.

\section{Mathematical Modeling of Drug Release Profiles}

To study the mechanism of 5FU release from the bilayer coated stents, the percentage of drug release data obtained from the in vitro release studies of the Si-PU $\mathrm{FU}-\mathrm{PEVA}$ and $\mathrm{Ba}-\mathrm{PU}_{\mathrm{FU}}-\mathrm{PEVA}$ stents were evaluated as a function of time (days) and applied to various mathematical models, using the Microsoft Excel add-in software program DDSolver. The goodness of fit of the experimentally observed 5FU release (at least $80 \%$ ) data to these models were evaluated and selected based on the three most popular statistical criteria; the adjusted coefficient of determination ( $R^{2}$ adjusted), the root mean squared error (RMSE), and the Akaike Information Criterion (AIC). The mathematical model that gave the highest $R^{2}$ adjusted value and smaller RMSE and ACI values best described the experimental drug release data. ${ }^{8,34-36}$

\section{Determination of Residual Solvents in Coated Stents} Determination of the total residual THF and DMF in the coated stents was conducted using gas chromatography (GC). For analysis of residual THF, Si-PU $\mathrm{FU}_{\text {and } \mathrm{Ba}-}$ $\mathrm{PU}_{\mathrm{FU}}$ stents were cut into pieces, accurately weighed
( $\sim 10 \mathrm{mg}$ ) and then $300 \mu \mathrm{L}$ of DMF was added to dissolve the PU coating ( $n=3$ for each type of stent). After $2 h$, the insoluble metal stent mesh was removed, dried in vacuo $\left(0.1 \mathrm{mbar}, 23^{\circ} \mathrm{C}\right)$ and weighed to determine the amount of basecoat dissolved in the solution. The concentration of THF in the solution was then determined using a Shimadzu GC-2010 gas chromatograph, equipped with a flame ionization detector (FID) and fitted with a Supelco $\mathrm{SPB}^{\circledR}-35$ capillary column $(30 \mathrm{~m} \times 0.32 \mathrm{~mm} \times 0.25 \mu \mathrm{m})$. Nitrogen was used as the carrier gas at a constant linear velocity of $56.5 \mathrm{~cm} / \mathrm{s}$, with injection port and detector temperatures of 200 and $250{ }^{\circ} \mathrm{C}$, respectively. A $1 \mu \mathrm{L}$ split injection (split ratio, 50:1) and a column temperature program of $40^{\circ} \mathrm{C}$ ( $1 \mathrm{~min}$ hold time) to $200{ }^{\circ} \mathrm{C}(2 \mathrm{~min}$ hold time) at $30{ }^{\circ} \mathrm{C} / \mathrm{min}$ were used. The concentration of residual DMF was determined using the same procedure, however, THF $(300 \mu \mathrm{L})$ was used instead to dissolve the PU basecoat. Determination of the time-dependent release of residual DMF from the coated bilayer stents was conducted alongside the 5FU release study in PBS (vide supra), using a Shimadzu Prominence HPLC system fitted with an Apollo C8 column. The procedural details related to the HPLC analysis of residual DMF are presented in SI, Table S6.

\section{Sterilization Conditions and Stent Testing}

Gamma irradiation sterilization was conducted by Steritech Pty Ltd (Dandenong, Victoria, Australia) on full-length Si-PU $\mathrm{FU}-\mathrm{PEVA}$ and $\mathrm{Ba}-\mathrm{PU}_{\mathrm{FU}}-\mathrm{PEVA}$ stents sealed in separate aluminum foil bags (SI, Figure S5). All samples were gamma-irradiated with a dose of 25 $\mathrm{kGy}$ at room temperature. The effect of gamma radiation on the stent performance was evaluated via in vitro drug release studies over a period of $\sim 14 \mathrm{~d}$, using the same experimental conditions as described previously (vide supra). The drug release profiles of the gamma-irradiated and non-irradiated (control) stents were quantitatively compared using the difference factor $f 1$ and similarity factor $f 2$, as recommended by the US FDA (for $f 1$ and $f 2$ equations, refer to $\underline{\mathrm{SI}}$, Figure S6). The $f 1$ and $f 2$ values for test stents versus control stents were calculated from the mean percentage drug release at each time point, with the application of DDSolver software package. ${ }^{8,35-38}$

\section{Stability Studies}

Si-PU $\mathrm{FU}_{-}-\mathrm{PEVA}$ and $\mathrm{Ba}-\mathrm{PU}_{\mathrm{FU}}-\mathrm{PEVA}$ stents were cut into small pieces of approximately equal weight and individually sealed in aluminum foil bags. The bags were then 
stored at either $25^{\circ} \mathrm{C} / 60 \%$ relative humidity (RH) or $40^{\circ}$ $\mathrm{C} / 75 \% \mathrm{RH}$ in separate stability chambers (Binder $\mathrm{GmbH}$, Tuttlingen, Germany) or at $4{ }^{\circ} \mathrm{C}$. Samples were withdrawn after 1 and 3 months, visually inspected, and the 5FU was extracted and quantified via HPLC.

\section{Results and Discussion \\ Fabrication of 5FU-Loaded GI Stents}

Various drug-polymer coating techniques, including spray coating, dip-coating, hot-melt coating and electrospinning, have been utilised for DES fabrication. However, among the available techniques, dip-coating is commonly accepted as the most simple, rapid and economic method for coating stent devices. ${ }^{11-13,39-42}$ Therefore, 5FUloaded nitinol stents were prepared by dip-coating the commercial GI nitinol stents (used for the treatment of GI cancers) sequentially with a drug-incorporated PU basecoat solution and a drug-free protective PEVA topcoat solution. ${ }^{32}$ While the PU base layer functions as the drug reservoir, the PEVA topcoat was intended to control the diffusion and premature burst release of the highly hydrophilic 5FU. ${ }^{31,43-45}$ Two types of GI nitinol stents (silicone membrane-covered and bare) were used (SI, Figure S1) in this study to investigate the applicability of the same drug-polymer formulations to different types of SEMS platforms via dip-coating, and thus compare potential differences in quality and drug release performance between the DESs. The fabricated dip-coated stents were referred to as $\mathrm{Si}-\mathrm{PU}_{\mathrm{FU}}-\mathrm{PEVA}$ and $\mathrm{Ba}-\mathrm{PU}_{\mathrm{FU}}-$ PEVA for silicone membrane-covered and bare nitinol stents coated with a 5FU-loaded PU layer then 5FU-free PEVA layer, respectively.

Interestingly, up to now there are no reported examples of 5FU-loaded stents prepared via dip-coating, other than our recent study ${ }^{32}$ on dip-coated 5FU-loaded nitinol stents. This potentially highlights the challenges of combining the hydrophilic 5FU with hydrophobic polymers (for example, PUs) in suitable formulations for dip-coating. Hence, a biostable ChronoFlex AL (PU)-based basecoat formulation which would provide a high 5FU loading was initially developed and optimized with a mixed solvent system (DMF:THF, 1:6.3, v/v). Subsequently, the 5FU-incorporated PU basecoat was used for dip-coating the nitinol stent platforms, resulting in Si-PU $\mathrm{FU}_{\mathrm{H}}$ and $\mathrm{Ba}-\mathrm{PU}_{\mathrm{FU}}$ stents with a $5 \mathrm{FU}$ loading of $6.5 \%(\mathrm{w} / \mathrm{w})$ (Figure 1). Following the PU-5FU base layer coating, a drug-free PEVA topcoat was dip-coated onto the base-coated $\mathrm{Si}-\mathrm{PU}_{\mathrm{FU}}$ and $\mathrm{Ba}-$
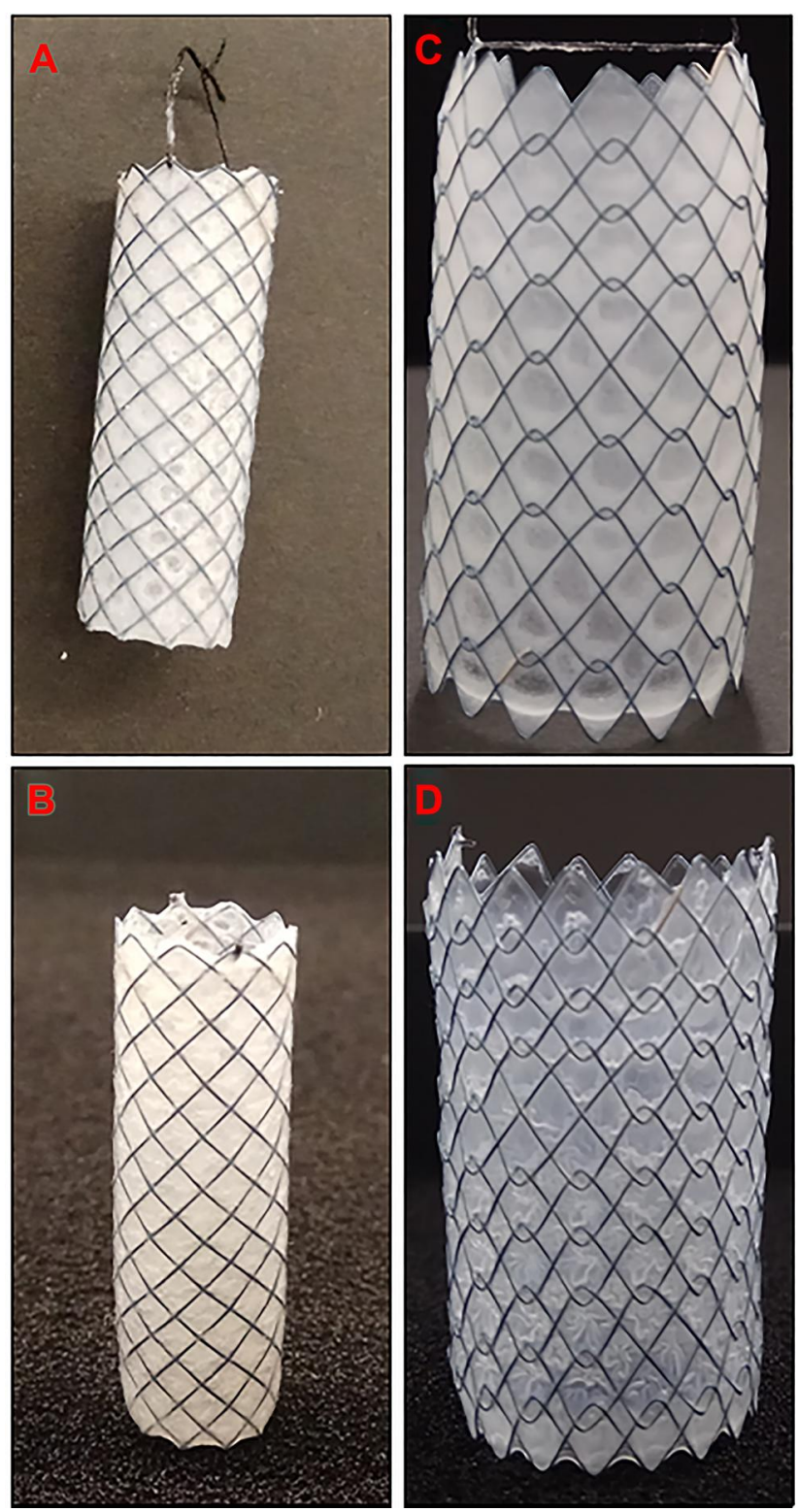

Figure I Fabricated 5FU-loaded gastrointestinal nitinol stents: (A) Si-PU FU stent (single-layer, base-coated only) and (B) Si-PU $\mathrm{FU}-\mathrm{PEVA}$ stent (double-layer, both base- and top-coated); (C) Ba-PU $\mathrm{FU}_{\mathrm{Fu}}$ stent (single-layer, base-coated only) and (D) $\mathrm{Ba}_{\mathrm{PU}} \mathrm{FU}_{\mathrm{PEVA}}$ stent (double-layer, both base- and top-coated).

$\mathrm{PU}_{\mathrm{FU}}$ stents using a $26 \% \quad(\mathrm{w} / \mathrm{v})$ DCM solution. Resultingly, Si-PU $\mathrm{FU}-\mathrm{PEVA}$ and $\mathrm{Ba}-\mathrm{PU}_{\mathrm{FU}}-\mathrm{PEVA}$ stents were fabricated (Figure 1) - with excellent reproducibility using the optimized coating formulations and the dip-coating process - for further in vitro drug release and quality assessment testing.

\section{Optimization of HPLC Method for 5FU Determination}

In addition to the HPLC method described in the current edition of the USP-NF, there are a number of HPLC 
methods that have been reported in the literature over the past 40 years for the determination of $5 \mathrm{FU}$ content in a variety of liquid mediums and/or mixtures. ${ }^{19,22,33,46-49}$ Considering the well-established reliability of the USP-NF analytical HPLC method, it was chosen and applied in the present study for 5FU determinations. ${ }^{33}$ However, as acknowledged by the US FDA in 21 CFR 211.194(a)(2), it is not necessary to validate further the reliability of the analytical methods specified in USP-NF, ${ }^{48}$ and therefore a full validation was not undertaken. Rather, we verified the suitability of the same USP method in our laboratory under real operating conditions (SI, Table S3) to assess the two important method validation parameters; accuracy and linearity (SI, Table S7 and Figure S7). ${ }^{46,48,49}$

Accuracy is usually defined as the closeness of the measured (experimental) quantity value to the true (or accepted true) quantity value of an analyte. ${ }^{46,48,49}$ The mean of accuracy (as recovery\%) and relative standard deviation percentage (RSD\%) values at eleven different 5FU concentrations $(0.5,1,2,4,6,8,10,20,30,40$, and $50 \mu \mathrm{g} / \mathrm{mL}$ ) in water showed acceptable recovery results with $\mathrm{RSD}$ values $<2 \%$. To check the linearity of the HPLC assay method, the calibration curve was constructed $^{49,50}$ with the same eleven concentrations of $5 \mathrm{FU}$ in water versus average peak area data. The linearity of the curve was determined by utilising a straight-line fit equation and analysis of the coefficient of determination $\left(R^{2}\right)$ values. ${ }^{46,49}$ As shown in SI, Figure S7, the values of the slope, intercept, and $R^{2}$ for $5 \mathrm{FU}$ calibration curve were found as $61,761,10,235$, and 1 , respectively, indicating that the linearity of the calibration curve was excellent. In addition, validation of the "stability" parameter was achieved by measuring the stability of $5 \mathrm{FU}$ in aqueous $10 \mathrm{mM}$ PBS solutions at three different $\mathrm{pH}$ values (5.8, 6.6, and 7.4) (vide infra). ${ }^{49}$ These results verify that the USP recommended HPLC method we used for 5FU analysis had an acceptable level of accuracy across the concentration range from 0.5 to $50 \mu \mathrm{g} / \mathrm{mL} 5 \mathrm{FU}$, and thus the method was found to be suitable and reliable for $5 \mathrm{FU}$ assay in the present study.

\section{Determination of Drug Loading and Content Uniformity of DESs}

Drug loading and content uniformity of $5 \mathrm{FU}$ was determined using weighed $\mathrm{Si}-\mathrm{PU}_{\mathrm{FU}}$ and $\mathrm{Ba}-\mathrm{PU} \mathrm{FU}_{\mathrm{FU}}$ stent pieces cut from along the length of individual stents. It was considered that the drug content from six sampled locations along the stent length would provide a reasonable approximation of the actual amount of 5FU present in the stents and its uniformity of distribution. The PU matrix for each stent piece was dissolved in DCM and the 5FU extracted into aqueous $1 \mathrm{~N}$ ammonium hydroxide prior to determination via HPLC (Table 1). The recovery efficiency (accuracy) of this process was validated with spiked 5FU samples (584.0 to $2648.0 \mu \mathrm{g} / \mathrm{mL}$ ) ( $\underline{\text { SI, Table }}$ $\underline{\mathrm{S} 8})$ and the mean ( \pm standard deviation (SD)) percentage recovery was found to be $99.4 \pm 1.9$, clearly indicating that the extraction procedure was suitable for the quantification of 5FU. For Si-PU $\mathrm{FU}_{\mathrm{FU}}$ and $\mathrm{Ba}-\mathrm{PU} \mathrm{FU}_{\mathrm{FU}}$ stent pieces the experimental 5FU loadings were observed to be almost identical to the theoretical 5FU loadings with low SD values and mean percentage recoveries of $\sim 98$ and $100 \%$, respectively, confirming the uniform distribution of $5 \mathrm{FU}$ within the PU base layer regardless of the stent platform type.

\section{FU Stability Studies in PBS}

In this study, to maximise the drug efficacy locally with significantly lower doses than used clinically in conventional systemic chemotherapy of GI cancers, we aimed to achieve a controlled 5FU release from the DESs over a course of several weeks to months. Thus, the stability of 5FU during its release from the $\mathrm{Si}-\mathrm{PU}_{\mathrm{FU}}-\mathrm{PEVA}$ and $\mathrm{Ba}-$ $\mathrm{PU}_{\mathrm{FU}}$-PEVA stents is important to appropriately characterise the release kinetics and to avoid suboptimal dosing of 5FU within or adjacent to tumor tissues. Previously, in vitro stability studies of $5 \mathrm{FU}$ under different conditions have shown it to be stable in alkaline media but undergoes hydrolysis in acidic media. ${ }^{51-55}$ As the $\mathrm{pH}$ of the GI tract (for example, colon) varies in response to a wide variety of physiological/pathophysiological conditions, ${ }^{56-59}$ DESs for the treatment of GI cancers are likely to be exposed

Table I Theoretical and Experimental Drug Loading Content for Dip-Coated Nitinol Stents $(n=6)$

\begin{tabular}{|c|c|c|c|c|}
\hline Sample & Weight (mg) & Theoretical 5FU Content ( $\mu \mathrm{g})$ & Experimental 5FU Content $(\mu \mathrm{g})^{a}$ & Recovery Yield (\%) \\
\hline Si-PU FU stent pieces & $14.93 \pm 0.38$ & $392.2 \pm 10.1$ & $384.9 \pm 16.4$ & $98.10 \pm 1.81$ \\
\hline $\mathrm{Ba}-\mathrm{PU}_{\mathrm{FU}}$ stent pieces & $9.85 \pm 0.67$ & $201.0 \pm 13.7$ & $201.2 \pm 14.7$ & $100.2 \pm 5.17$ \\
\hline
\end{tabular}

Notes: ${ }^{a}$ All experimental amounts of $5 F U$ were measured by HPLC; ${ }^{b}$ Recovery yield (\%) was calculated from the ratio of experimental to theoretical $5 F U$ content; All values are expressed as mean \pm SD. 
to variable $\mathrm{pH}$ levels, and therefore, we studied the in vitro stability of $5 \mathrm{FU}(54.57 \pm 0.79 \mu \mathrm{g} / \mathrm{mL})$ in $10 \mathrm{mM}$ PBS at $\mathrm{pH}$ values of 5.8, 6.6, and 7.4 over a period of $100 \mathrm{~d}$. The concentration of $5 \mathrm{FU}$ at each timepoint was measured via HPLC.

For all three $\mathrm{pH}$ conditions tested, there were no observable colour changes or turbidity, and no crystallization was visible microscopically at 40 -fold magnification after $100 \mathrm{~d}$ of storage at $37^{\circ} \mathrm{C}$. The $\mathrm{pH}$ of the $5 \mathrm{FU}$ solutions did not show any significant changes between day 0 and day 100 (SI, Table S9). For all pH conditions tested, there was negligible variation in the concentration of $5 \mathrm{FU}$ as indi-

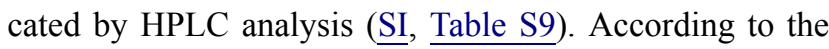
US FDA, a drug substance is considered stable if the lower bound of the $95 \%$ confidence interval (CI) on the mean concentration remains above $90 \%$ of its initial concentration. ${ }^{52}$ Our results are fully compliant with the US FDA recommended stability requirements and prove that $5 \mathrm{FU}$ can be considered chemically stable for at least $100 \mathrm{~d}$ within the experimental limits of this study.

\section{In vitro Release of 5FU from DESs}

In vitro release of $5 \mathrm{FU}$ from the $\mathrm{Si}-\mathrm{PU}_{\mathrm{FU}}-\mathrm{PEVA}$ and $\mathrm{Ba}-$ $\mathrm{PU}_{\mathrm{FU}}-\mathrm{PEVA}$ stents was conducted in PBS $(10 \mathrm{mM}, \mathrm{pH} 7.4$, $37{ }^{\circ} \mathrm{C}$ ) and monitored at regular intervals via HPLC. To ensure sink conditions were maintained the total 5FU loading and 5FU solubility in the medium were determined $(7.65 \pm 1.50 \mathrm{mg} / \mathrm{mL})$ and the volume of release media was calculated accordingly. The $5 \mathrm{FU}$ release from the $\mathrm{Si}-$ $\mathrm{PU}_{\mathrm{FU}}-\mathrm{PEVA}$ and $\mathrm{Ba}-\mathrm{PU}_{\mathrm{FU}}-\mathrm{PEVA}$ stents presented as asymptotic profiles with distinctively different release periods (Figure 2), even though the same dip-coating formulation and process parameters were applied to fabricate both DESs. For the Si-PU $\mathrm{FU}-\mathrm{PEVA}$ stents a gradual and sustained release of 5FU was observed over a period of $161 \mathrm{~d}$, reaching a maximum release of $\sim 86 \%$ $\left(\sim 479 \mu \mathrm{g} / \mathrm{cm}^{2}\right)$. In contrast, the Ba-PU $\mathrm{FU}_{\mathrm{FU}}$-PEVA stents provided biphasic release kinetics with an initial burst effect $(\sim 22 \%)$ during the first day followed by a relatively sustained release up to $30 \mathrm{~d}$, reaching a maximum release of $\sim 94 \%\left(\sim 215 \mu \mathrm{g} / \mathrm{cm}^{2}\right)$. As a point of reference, release studies were also conducted on single-layer $\mathrm{Si}-\mathrm{PU}_{\mathrm{FU}}$ stents (data not shown), which displayed a rapid release of 5FU (100\% in 4 d) due to its high aqueous solubility (octanol/ water partition coefficient, $P_{o w}=-0.83^{60,61}$ ) and highlighted the importance of the additional PEVA topcoat in modulating the release kinetics. Similar results have also been reported by others, with Shin et al noting the rapid release
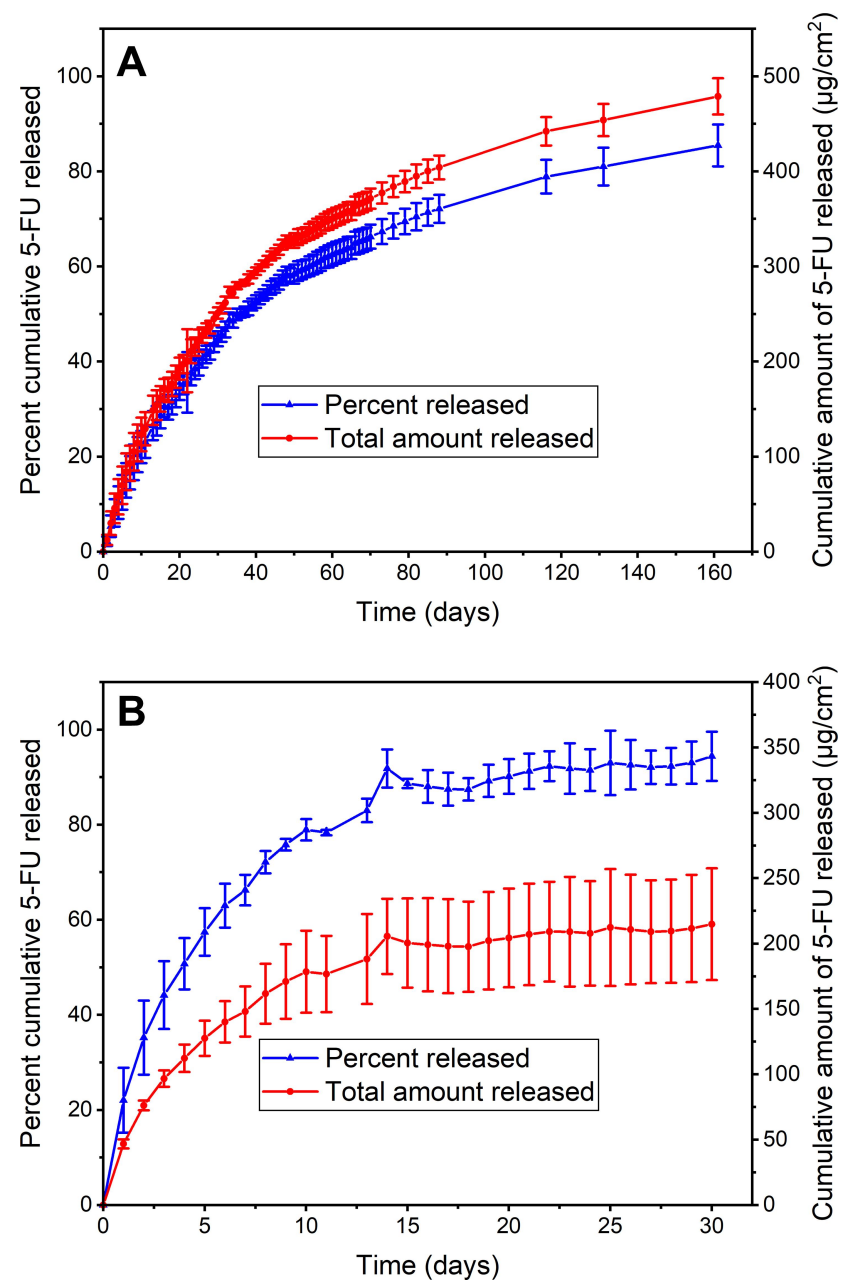

Figure 2 In vitro release profile of 5 -fluorouracil (5-FU) from (A) Si-PU $\mathrm{FU}_{-\mathrm{PEVA}}$ stents over $16 \mathrm{I}$ days and (B) Ba-PU $\mathrm{FU}-\mathrm{PEVA}$ stents over 30 days in phosphate buffer saline ( $10 \mathrm{mM}, \mathrm{pH} 7.4)$. Data represents $\mathrm{n}=3$, mean \pm standard deviation.

of gemcitabine from single layer ChronoFlex AL (PU) films in the absence of PEVA, ${ }^{62}$ and various others demonstrating diffusion-controlled drug release from PEVA-based polymer matrices. ${ }^{18,19,63,64}$

The disparity of $5 \mathrm{FU}$ release periods between the two drug-loaded stents was attributed to structural (including geometry) differences and the effect of this on the deposited polymer coatings. The Si-covered stents possessed different surface topographies and thickness (for both the PU-5FU basecoat and PEVA topcoat) as compared to that of the bare stents. ${ }^{32}$ Furthermore, in the case of Si-covered stents the primary $\mathrm{Si}$ membrane backing layer results in abluminal and luminal PU-5FU basecoat layers, whereas only a single PU-5FU basecoat layer is formed over the mesh interstices of the bare stents.

Invariably, the successful performance of DESs depends on the delivery of an effective drug dose with controlled 
drug release kinetics. ${ }^{3,16}$ The in vitro release studies showed that both the $\mathrm{Si}-\mathrm{PU}_{\mathrm{FU}}-\mathrm{PEVA}$ and $\mathrm{Ba}-\mathrm{PU} \mathrm{FU}_{\mathrm{FU}}-\mathrm{PEVA}$ stents can provide a sustained release of $5 \mathrm{FU}$ across two different time scales, which may be useful in different scenarios. According to the European Society of Gastrointestinal Endoscopy (ESGE) guidelines, the placement of SEMS is recommended when the patient's expected survival time is $>$ 4 months, ${ }^{9}$ and therefore, the sustained release provide by the $\mathrm{Si}-\mathrm{PU}_{\mathrm{FU}}$-PEVA stent ( $>5$ months) might make it a promising candidate for the treatment of various obstructing GI cancers. In contrast, the relatively fast and short-term 5FU release from the $\mathrm{Ba}-\mathrm{PU}_{\mathrm{FU}}$-PEVA stents may be particularly effective for the treatment of palliative GI cancer patients, many of which would be likely to continue with the stent on their GI tract until death.

Furthermore, chemotherapeutics consistently released from DESs over a sustained period of time are more likely to result in optimal diffusion and uptake by the surrounding cancer cells over several cell division cycles and may lead to better control of GI tumor cell replication and subsequent cancer spread. ${ }^{1,65}$ Hence, GI DESs could potentially inhibit the growth of cancer cells around the stent more efficiently than conventional systemic administration of chemotherapeutics and non-DESs. ${ }^{6,9,10,13,18-20,23,66-68}$

\section{Mathematical Modeling of Drug Release Profiles}

To study the mechanism of 5FU release from the bilayer coated DESs, various mathematical models (SI, Table S10) were applied to the drug release (at least $80 \%$ ) data obtained from in vitro release studies in PBS..$^{8,34,35}$ The goodness of fit of the experimental release profiles was evaluated using three common statistical criteria in combination; the adjusted $R^{2}$, the RMSE, and the AIC. ${ }^{8,34,35}$ For the Si-PU $\mathrm{FU}-\mathrm{PEVA}$ and $\mathrm{Ba}-\mathrm{PU}_{\mathrm{FU}}-\mathrm{PEVA}$ stents the experimental release data were best fitted by the Weibull model and Peppas-Sahlin model, respectively. The $\beta$ value of the Weibull model is the shape parameter which describes the release curve as either sigmoidal (S-shaped) with upward bend followed by a turning point (when $\beta>1$ ) or exponential (when $\beta=1$ ), or parabolic with a steeper initial slope and rest consistent with the exponential (when $\beta<1) .{ }^{35,38,69}$ The shape parameter $(\beta$ value) of the Weibull model was calculated to be $<0.75$ (SI, Table S10), indicating a more pronounced parabolic shape to the release profile ${ }^{35,38}$ that is consistent with a predominantly Fickian diffusion-controlled mechanism for the Si-PU $\mathrm{FU}_{\mathrm{F}}$-PEVA stents. ${ }^{69}$ The Peppas-Sahlin model describes drug release as a combination of the Fickian diffusion and polymer phase transition from a semi-rigid to a flexible structure that corresponds to relaxation of the polymer chains. ${ }^{34,35}$ However, determination of the Peppas-Sahlin model rate constants for the $\mathrm{Ba}-\mathrm{PU}_{\mathrm{FU}}-$ PEVA stents $\left(k_{1}=24.038\right.$ and $\left.k_{2}=-1.694\right)$ implied that Fickian diffusion was the predominant factor because of a larger $k_{1}$ value.

\section{Determination of Residual Solvents from Manufacturing of DESs}

During the stent coating process, several organic solvents were used to prepare dip-coating solutions: THF (boiling point $\left.(\mathrm{BP})=66{ }^{\circ} \mathrm{C}\right)$, DMF $\left(\mathrm{BP}=153{ }^{\circ} \mathrm{C}\right)$, and DCM (BP $\left.=40{ }^{\circ} \mathrm{C}\right) .{ }^{70}$ While the majority of the solvents are evaporated during the stent drying process following dip-coating, it is conceivable that residual traces remain entrapped within the polymeric matrices, especially for less volatile solvents. Given the inherent toxicities of these solvents, the amount of THF and DMF in the Si-PU $\mathrm{FU}-\mathrm{PEVA}$ and Ba-PU $\mathrm{FU}_{\mathrm{FU}}-\mathrm{PEVA}$ stents was quantified, disregarding DCM due to its low BP. The polymeric coatings on stent sections were dissolved and the solutions analyzed via GC, which determined that no residual THF was present in either the Si-PU $\mathrm{FU}-\mathrm{PEVA}$ or Ba-PU $\mathrm{FU}-\mathrm{PEVA}$ stents ( $\underline{\text { SI, Figure S8) }}$. However, residual DMF was detected at levels of $1201 \pm$ 115 and $1319 \pm 194$ ppm (SI, Figure S9) respectively, both of which are above the FDA recommended concentration limit of $880 \mathrm{ppm}(\underline{\mathrm{SI}}, \underline{\text { Table S11}})^{71}$

The relatively high amounts of residual DMF in the coated stents may be correlated with the drying time and process (oven drying), and further optimization of the process is likely to reduce residual levels. Nevertheless, the inherent design of DESs is that they slowly release their payload over time, and it was hypothesized that a gradual release of DMF would also be observed. Therefore, the release of DMF from the stents over time was measured to better understand the true DMF exposure levels and assess the compliance of the stents (Figure 3). Day 1-7 samples were collected from the 5FU release study in PBS (pH 7.4, $37^{\circ} \mathrm{C}$ ) and analyzed for DMF via

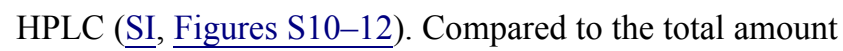
of DMF extracted from the stents, the daily release of DMF was significantly lower (Figure 3), and well below the FDA permitted daily exposure (PDE) limit of $8.8 \mathrm{mg}$ (SI, Table S11). For Si-PU $\mathrm{FU}-\mathrm{PEVA}$ and $\mathrm{Ba}-\mathrm{PU}_{\mathrm{FU}}-\mathrm{PEVA}$ 


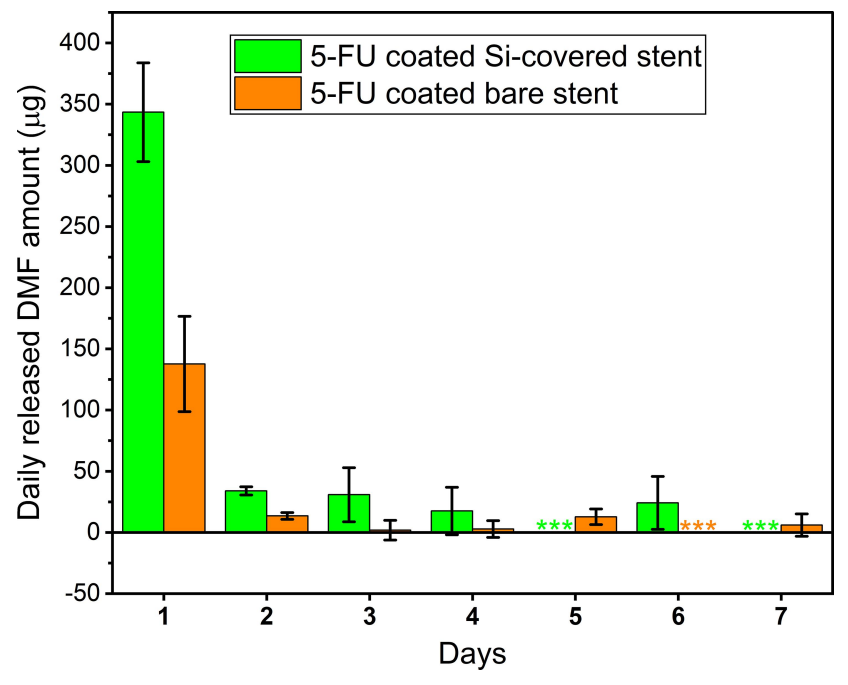

Figure 3 Amount of $\mathrm{N}, \mathrm{N}$-dimethylformamide (DMF) detected (by HPLC) per day over seven successive days after in vitro release from the Si-PU $\mathrm{FU}_{-P E V A}$ or Ba$\mathrm{PU}_{\mathrm{FU}}-\mathrm{PEVA}$ stents in phosphate buffered saline $(10 \mathrm{mM}, \mathrm{PH} 7.4)$. Three asterisks (***) reflect DMF amount below the HPLC method quantitation limit of 5 ppm. All values represent mean $(n=3) \pm$ standard deviation.

stents, the highest amount of DMF was detected after the first day (343.4 and $137.7 \mu \mathrm{g}$, respectively), which then decreased significantly on subsequent days. These results demonstrated that the amount of residual DMF that could leach from the stents in a single day after placement is unlikely to cause DMF-related localized or systemic toxicities. This claim was further confirmed by in vitro cytotoxicity tests with drug-free (blank control) PU coated stents, which showed the (relative) viability of HCT 116 human colon cancer cells was almost similar $(\sim 97 \%)$ to untreated (media) control. ${ }^{32}$

\section{Effect of Sterilization on Stents}

Sterilization of medical devices and DESs with ionizing radiation (for example, gamma irradiation) can potentially lead to drug or polymer degradation that may result in unanticipated effects on the critical quality attributes of DESs, such as loss of coating integrity, and drug and polymer carrier instability. However, according to FDA recommendations, in vitro drug release testing is a powerful tool for assessing any changes in DES critical performance parameters, ${ }^{8}$ and therefore, the $5 \mathrm{FU}$ release profiles were compared for the stents before and after gamma irradiation $\left(25 \mathrm{kGy}^{72}\right.$ ) (Figure 4). Overall, no significant differences were noted in the release profiles for irradiated and non-irradiated stents, which was further confirmed by calculation of the difference $(f 1)$ and similarity ( $f 2)$ factors. Generally two dissolution profiles are
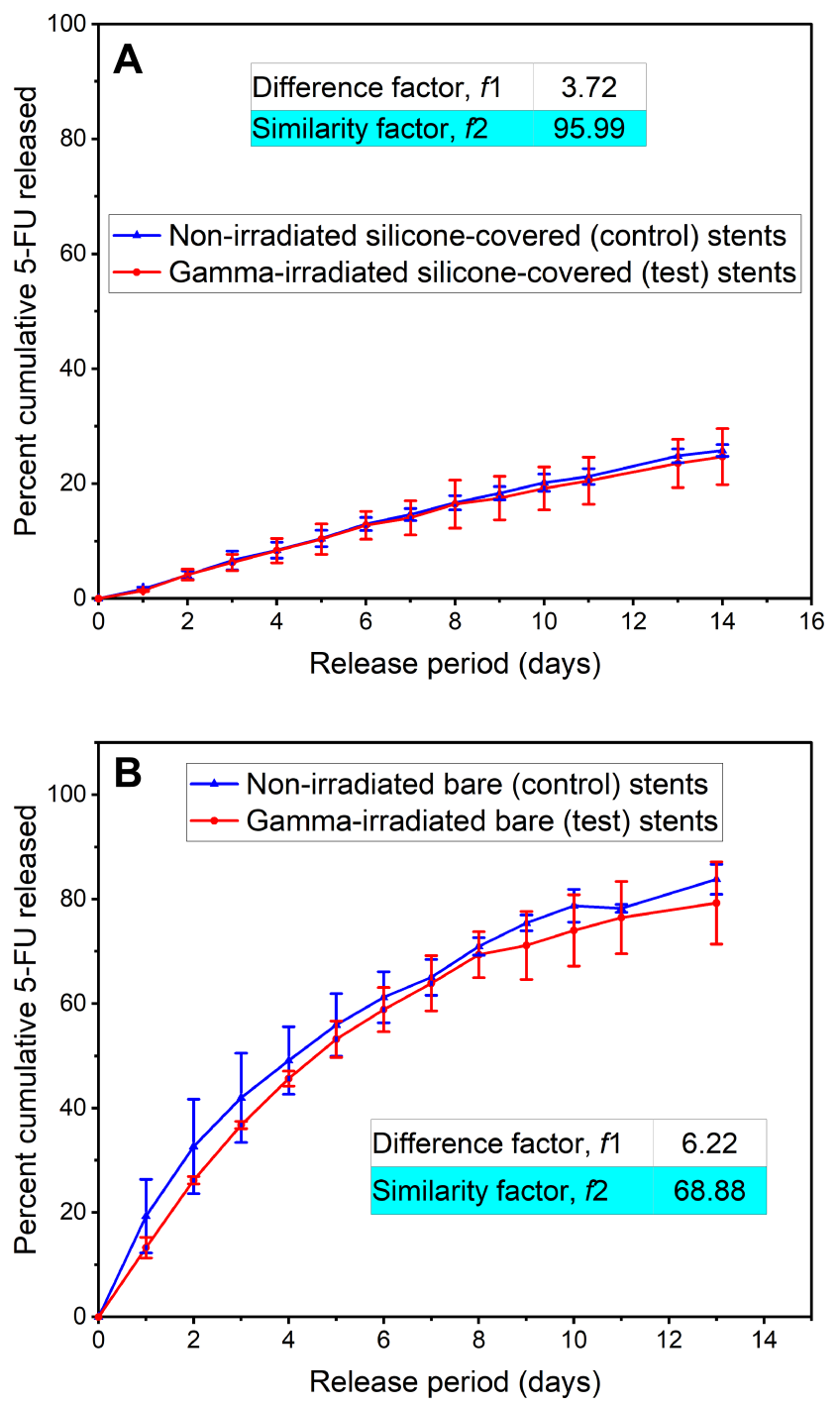

Figure 4 In vitro percentage cumulative 5-fluorouracil (5-FU) release curves from (A) $\mathrm{Si}-\mathrm{PU}_{\mathrm{FU}}-\mathrm{PEVA}$ stents over 14 days and (B) Ba-PU $\mathrm{FU}-\mathrm{PEVA}$ stents over 13 days in phosphate buffered saline $\left(10 \mathrm{mM}, \mathrm{pH} 7.4,37^{\circ} \mathrm{C}\right)$. Data for control (non-irradiated) and gamma-irradiated stents ( $\mathrm{n}=2$ for all data points, mean \pm standard deviation).

considered similar when $f 1$ value range between 0 and 15 and $f 2$ value range between 50 and 100 , as suggested by the US FDA. ${ }^{36-38}$ For the irradiated and non-irradiated Si$\mathrm{PU}_{\mathrm{FU}}-\mathrm{PEVA}$ and $\mathrm{Ba}-\mathrm{PU}_{\mathrm{FU}}-\mathrm{PEVA}$ stents the $f 1$ and $f 2$ values were within acceptable limits $(f 1=3.72$ and $f 2=$ 95.99 for $\mathrm{Si}-\mathrm{PU}_{\mathrm{FU}}-\mathrm{PEVA} ; f 1=6.22$ and $f 2=68.88$ for Ba$\mathrm{PU}_{\mathrm{FU}}-\mathrm{PEVA}$ ) indicating that gamma irradiation sterilization had no significant effect on the in vitro $5 \mathrm{FU}$ release.

\section{Stability Studies}

To investigate the stability of $5 \mathrm{FU}$ in the stents and the integrity of the polymer coating under the influence of temperature/humidity variations over time, stability studies were conducted with the $\mathrm{Si}-\mathrm{PU}_{\mathrm{FU}}-\mathrm{PEVA}$ and $\mathrm{Ba}-\mathrm{PU}_{\mathrm{FU}^{-}}$ 
PEVA stents under the storage conditions prescribed in the International Conference on Harmonisation (ICH) Q1A (R2) guidelines. ${ }^{73,74}$ The stents were individually packed in aluminum foil bags (SI, Figure S5) and stored at $25^{\circ} \mathrm{C} /$ $60 \% \mathrm{RH}$ or $40{ }^{\circ} \mathrm{C} / 75 \% \mathrm{RH}$, and evaluated after 1 and 3 months for appearance, weight variation, drug content, degradation products/impurities, and in vitro drug release (SI, Table S12).

The appearance of the stents (abluminal and luminal surfaces) was visualised via brightfield microscopy (40× magnification) before and after storage, which revealed no significant differences and implied that the stents are physically stable under the conditions tested over a period of three months; this was further supported by the absence of any weight changes. To determine the stability of 5FU, the drug content in the Si-PU $\mathrm{FU}_{-P E V A}$ or $\mathrm{Ba}-\mathrm{PU}_{\mathrm{FU}}-\mathrm{PEVA}$ stents was determined via HPLC over the 3 months storage and compared to the initial amount, which revealed no significant change (SI, Table S12).

However, to assess the effect of accelerated storage conditions on the 5FU release from the Si-PU $\mathrm{FU}_{-P E V A}$ and $\mathrm{Ba}-\mathrm{PU}_{\mathrm{FU}}-\mathrm{PEVA}$ stents, the release profiles of stents stored at $40{ }^{\circ} \mathrm{C} \pm 2{ }^{\circ} \mathrm{C} / 75 \% \mathrm{RH} \pm 5 \% \mathrm{RH}$ for 3 months were compared to stents stored at $4{ }^{\circ} \mathrm{C}$ (Figure 5). For both the $\mathrm{Si}-\mathrm{PU}_{\mathrm{FU}}-\mathrm{PEVA}$ and $\mathrm{Ba}-\mathrm{PU}_{\mathrm{FU}}-\mathrm{PEVA}$ stents stored under accelerated conditions the $f 1$ and $f 2$ factors were within acceptable limits versus stents stored at $4{ }^{\circ} \mathrm{C}$ (SI, Table S12), and univariate analysis of variance (ANOVA) indicated that the 5FU release profiles were not significantly different statistically. Together, these results imply that the stents are stable under accelerated storage conditions over 3 months without alteration in their in vitro drug release profiles.

\section{Conclusions}

Two anticancer drug-eluting stent (DES) platforms were fabricated successfully via dip-coating of either silicone membrane-covered or bare self-expanding GI nitinol stents sequentially with a $5 \mathrm{FU}(6.5 \% \mathrm{w} / \mathrm{w})$-incorporated polyurethane (PU) basecoat and a blank (drug-free) poly (ethylene-co-vinyl acetate) (PEVA) topcoat. Optimization of the stent coating formulations and dip-coating process parameters allowed the highly hydrophilic 5FU to be successfully encapsulated in a hydrophobic PU polymer matrix, and top-coating with PEVA allowed the burst release of $5 \mathrm{FU}$ to be controlled effectively. Determination of drug loading content in the stents confirmed that the 5FU was uniformly distributed throughout
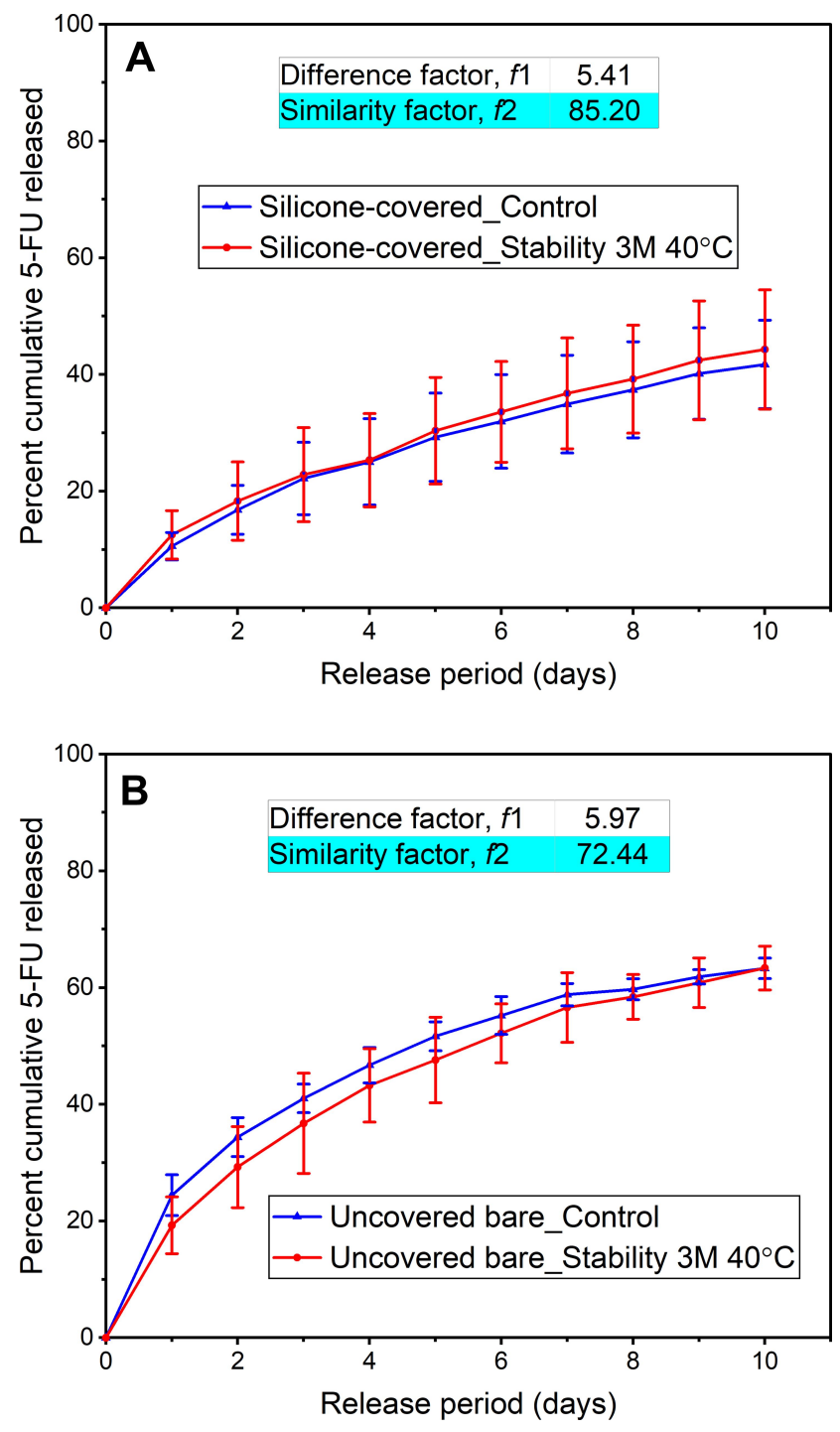

Figure 5 Cumulative percent of 5 -fluorouracil (5-FU) released in vitro from the representative control and accelerated stability $\left(40{ }^{\circ} \mathrm{C}\right.$ and $75 \%$ relative humidity) test of the (A) Si-PU $\mathrm{FU}-\mathrm{PEVA}$ and (B) Ba-PU $\mathrm{FU}-\mathrm{PEVA}$ stents. Data from 3-month stability samples ( $n=3 \pm$ standard deviation). For drug release profiles to be similar, difference factor $(f 1)$ and similarity factor ( $f 2)$ need to be $\leq 15$ and $\geq 50$ (50 to 100 ), respectively.

the PU matrix without significant variation in its content along the length of an individual coated stent. With the chemical stability of $5 \mathrm{FU}$ in the in vitro release medium confirmed for at least $100 \mathrm{~d}$, drug release studies demonstrated controlled and sustained 5FU release profiles across two different time scales (161 and $30 \mathrm{~d}$ ), which may be useful in different clinical scenarios. No residual THF was detected in either of the coated 5FU-loaded stents. While residual DMF was detected, the amount that leached from the stents in a single day was determined to be significantly lower than the FDA recommended daily exposure limit of $8.8 \mathrm{mg}$, and is unlikely to cause any DMF-related local/systemic toxicities. In 
addition, the 5FU-loaded stents exhibited no significant change in the in vitro drug release profiles after sterilization with gamma radiation, or after incubation for 3 months under accelerated storage conditions.

The series of tests performed in this study are typically considered quality assessment tests recommended to be performed during development and commercial production of DESs. However, other aspects of DESs, such as mechanical characteristics of the polymer coating which may influence the delivery and deployment of DESs in vivo, are required to be explored further, before taking this preclinical experimental study of GI DESs into confirmatory animal and human studies. Nevertheless, the results from the critical quality attributes tested herein comply with the current FDA regulatory requirements for DESs, suggesting the newly developed 5FU-eluting DESs could be potential candidates for effective chemotherapeutic treatment of gastrointestinal cancers and associated obstructions.

\section{Disclosure}

The authors report no conflicts of interest in this work.

\section{References}

1. Arafat M, Fouladian P, Blencowe A, Albrecht H, Song Y, Garg S. Drug-eluting non-vascular stents for localised drug targeting in obstructive gastrointestinal cancers. $J$ Controlled Release. 2019;308:209-231. doi:10.1016/j.jconrel.2019.07.001

2. European Medicines Agency. EMEA/CHMP/EWP/110540/2007. Guideline on the clinical and non clinical evaluation during the consultation procedure on medicinal substances contained in drug-eluting (medicinal substance-eluting) coronary stents. Available from: http:// www.ema.europa.eu/docs/en_GB/document_library/Scientific_guide line/2009/09/WC500003275.pdf. Accessed July 15, 2017.

3. Guo S-R, Chen W-L, Rong H-J LF. Stents as a platform for drug delivery AU - Lei, Lei. Expert Opin Drug Deliv. 2011;8(6):813-831. doi:10.1517/17425247.2011.572068

4. Baron TH Enteral stents for the management of malignant colorectal obstruction. Available from: https://www.uptodate.com/contents/ent eral-stents-for-the-management-of-malignant-colorectal-obstruction? source $=$ search_result\&search $=$ enteral $\% 20$ stent\&selectedTitle $=2 \sim 22$. Accessed June 30, 2017.

5. Boam AB. Regulatory issues facing the development of drug-eluting stents: a US FDA perspective. Expert Rev Med Devices. 2006;3 (3):297-300. doi:10.1586/17434440.3.3.297

6. Wu P, Grainger DW. Drug/device combinations for local drug therapies and infection prophylaxis. Biomaterials. 2006;27(11):24 50-2467. doi:10.1016/j.biomaterials.2005.11.031

7. Schmidt W, Lanzer P. Instrumentation. In: Lanzer P, editor. CatheterBased Cardiovascular Interventions: A Knowledge-Based Approach. Berlin, Heidelberg: Springer Berlin Heidelberg; 2013:445-472.

8. Food and Drug Administration Center for Devices and Radiological Health (CDRH). Guidance for Industry: Coronary Drug-Eluting Stents-Nonclinical and Clinical Studies (Draft). Rockville, MD, USA: Food and Drug Administration (FDA); 2008:89.
9. Kim S-Y, Kim M, Kim M-K, et al. Paclitaxel-eluting nanofiber-covered self-expanding nonvascular stent for palliative chemotherapy of gastrointestinal cancer and its related stenosis. Biomed Microdevices. 2014;16(6):897-904. doi:10.1007/s10544-01 4-9894-9

10. Kwak TW, Lee HL, Song YH, et al. Vorinostat-eluting poly (DL-lactide-co-glycolide) nanofiber-coated stent for inhibition of cholangiocarcinoma cells. Int J Nanomedicine. 2017;12:7669-7680. doi: 10.2147/IJN.S141920

11. Lee DK, Kim HS, Kim K-S, et al. The effect on porcine bile duct of a metallic stent covered with a paclitaxel-incorporated membrane. Gastrointest Endosc. 2005;61(2):296-301. doi:10.1016/S0016-510 7(04)02570-2

12. Lee JW, Yang S-G NK. Gemcitabine-releasing polymeric films for covered self-expandable metallic stent in treatment of gastrointestinal cancer. Int J Pharm. 2012;427(2):276-283. doi:10.1016/j.ijpharm.20 12.02 .016

13. Moon S, Yang S-G NK. An acetylated polysaccharide-PTFE membrane-covered stent for the delivery of gemcitabine for treatment of gastrointestinal cancer and related stenosis. Biomaterials. 2011;32 (14):3603-3610. doi:10.1016/j.biomaterials.2011.01.070

14. Clark JW, Grothey A Systemic chemotherapy for metastatic colorectal cancer. Available from: https://www.uptodate.com/contents/sys temic-chemotherapy-for-metastatic-colorectal-cancer-completed-clini cal-trials/print?source=see link. Accessed July 3, 2017.

15. Pinto AC, Moreira J, Simoes SR. Combination chemotherapy in cancer: principles, evaluation and drug delivery strategies. In: Ozdemir O, editor. Current Cancer Treatment - Novel Beyond Conventional Approaches. InTech; 2011:693-714.

16. Thipparaboina R, Khan W, Domb AJ. Eluting combination drugs from stents. Int $J$ Pharm. 2013;454(1):4-10. doi:10.1016/j.ijpharm. 2013.07.005

17. National Cancer Institute. Drugs Approved for colon and rectal cancer. https://www.cancer.gov/about-cancer/treatment/drugs/colorec tal. Available from: Accessed July 3, 2017.

18. Guo Q, Guo S, Wang Z. A type of esophageal stent coating composed of one 5-fluorouracil-containing EVA layer and one drug-free protective layer: in vitro release, permeation and mechanical properties. J Controlled Release. 2007;118(3):318-324. doi:10.1016/j.jconrel.20 06.12 .030

19. Guo S-R, Wang Z-M, Zhang Y-Q, et al. In Vivo Evaluation of 5-Fluorouracil-Containing Self-Expandable Nitinol Stent in Rabbits: efficiency in Long-Term Local Drug Delivery. J Pharm Sci. 2010;99 (7):3009-3018. doi:10.1002/jps.22066

20. Li G, Chen Y, Hu J, et al. A 5-fluorouracil-loaded polydioxanone weft-knitted stent for the treatment of colorectal cancer. Biomaterials. 2013;34(37):9451-9461. doi:10.1016/j.biomaterials.2013.08.055

21. Olukman M, Sanli O, Solak EK. Release of Anticancer Drug 5-Fluorouracil from Different Ionically Crosslinked Alginate Beads. J Biomater Nanobiotechnol. 2012;3(4):12. doi:10.4236/jbnb.2012.34048

22. Fouladian P, Kohlhagen J, Arafat M, et al. Three-dimensional printed 5-fluorouracil eluting polyurethane stents for the treatment of oesophageal cancers. Biomater Sci. 2020;8(23):6625-6636. doi:10.1039/ D0BM01355B

23. Liu J, Wang Z, Wu K, et al. Paclitaxel or 5-fluorouracil/esophageal stent combinations as a novel approach for the treatment of esophageal cancer. Biomaterials. 2015;53(SupplementC):592-599. doi:10. 1016/j.biomaterials.2015.03.009

24. Wang Z, Liu J, Wu K, et al. Nitinol stents loaded with a high dose of antitumor 5-fluorouracil or paclitaxel: esophageal tissue responses in a porcine model. Gastrointest Endosc. 2015;82(1):153-160.e151. doi:10.1016/j.gie.2015.02.034

25. Armstrong EJ, Waltenberger J, Rogers JH. Percutaneous coronary intervention in patients with diabetes: current concepts and future directions. J Diabetes Sci Technol. 2014;8(3):581-589. doi:10.1177/ 1932296813517058 
26. Htay T, Liu MW. Drug-Eluting Stent: a Review and Update. Vasc Health Risk Manag. 2005;1(4):263-276. doi:10.2147/vhrm.2005. 1.4.263

27. Kwon H, Park S. Local delivery of antiproliferative agents via stents. Polymers. 2014;6(3):755. doi:10.3390/polym6030755

28. Mani G, Feldman MD, Patel D, Agrawal CM. Coronary stents: a materials perspective. Biomaterials. 2007;28(9):1689-1710.

29. Rizas Konstantinos D, Mehilli J. Stent Polymers. Circ Cardiovasc Interv. 2016;9(6):e02943. doi:10.1161/CIRCINTERVENTIONS.11 5.002943

30. Hsu LSF, Marrs TC. Determination of 5-Fluorouracil in human plasma by high-pressure ion-exchange chromatography. Ann Clin Biochem. 1980;17(5):272-276. doi:10.1177/000456328001700510

31. Chappa RA, Hergenrother RW, Wadman SA, Wormuth KR Coating systems for the controlled delivery of hydrophilic bioactive agents. Google Patents; 2013.

32. Arafat M, Fouladian P, Wignall A, et al. Development and in vitro evaluation of 5-fluorouracil-eluting stents for the treatment of colorectal cancer and cancer-related obstruction. Pharmaceutics. 2021;13 (1):17. doi:10.3390/pharmaceutics 13010017

33. United States Pharmacopeial Convention. Fluorouracil. United States Pharmacopeial Convention; 2019.

34. Freire MCLC, Alexandrino F, Marcelino HR, et al. Understanding Drug Release Data through Thermodynamic Analysis. Materials. 2017;10(6):651. doi:10.3390/ma10060651

35. Zhang Y, Huo M, Zhou J, et al. DDSolver: an add-in program for modeling and comparison of drug dissolution profiles. AAPS $J$. 2010;12(3):263-271. doi:10.1208/s12248-010-9185-1

36. Zuo J, Gao Y, Bou-Chacra N, Löbenberg R. Evaluation of the DDSolver Software Applications. Biomed Res Int. 2014;20 14:204925. doi: $10.1155 / 2014 / 204925$

37. Shaikh M, Roy Choudhury N, Knott R, Kanwar JR, Garg S. Effect of polymer microstructure on the docetaxel release and stability of polyurethane formulation. Eur $J$ Pharm Biopharmaceutics. 2016;101:82-89. doi:10.1016/j.ejpb.2016.01.015

38. Yuksel N, Kanık AE, Baykara T. Comparison of in vitro dissolution profiles by ANOVA-based, model-dependent and -independent methods. Int J Pharm. 2000;209(1):57-67. doi:10.1016/S0378-5173 (00)00554-8

39. Chung MJ, Kim H, Kim KS, Park S, Chung JB, Park SW. Safety evaluation of self-expanding metallic biliary stents eluting gemcitabine in a porcine model. J Gastroenterol Hepatol. 2012;27 (2):261-267. doi:10.1111/j.1440-1746.2011.06866.x

40. Jang SI, Kim JH, Kim M, et al. Porcine feasibility and safety study of a new paclitaxel-eluting biliary stent with a Pluronic-containing membrane. Endoscopy. 2012;44(09):825-831. doi:10.1055/s-0032-13 09881

41. Lee SS, Shin JH, Han JM, et al. Histologic influence of paclitaxel-eluting covered metallic stents in a canine biliary model. Gastrointest Endosc. 2009;69(6):1140-1147. doi:10.1016/j.gie.2008. 08.005

42. Seo EH, Na K. Polyurethane membrane with porous surface for controlled drug release in drug eluting stent. Biomater Res. 2014;18 (1): 15 .

43. Lei L, Liu X, Guo S, Tang M, Cheng L, Tian L. 5-Fluorouracilloaded multilayered films for drug controlled releasing stent application: drug release, microstructure, and ex vivo permeation behaviors. $J$ Controlled Release. 2010;146(1):45-53. doi:10.1016/j.jconrel.20 10.05.017

44. Thakkar A, Raval A, Mandal R, et al. Development and evaluation of drug eluting stent having biphasic release from a single layer of biodegradable polymer. J Med Device. 2013;7(1). doi:10.1115/ 1.4023414

45. Whitbourne RJ, Chamberlain AM, Hullihen DG, Rosebrough SF, Calistri-Yeh M Medicated stent having multi-layer polymer coating. Google Patents; 2012.
46. Amasya G, Gumustas M, Badilli U, Ozkan SA, Tarimci N. Development of a HILIC method for the determination of 5-fluorouracil from nano drug delivery systems and rat skin extracts. J Pharm Biomed Anal. 2018;154:285-293. doi:10.1016/j. jpba.2018.03.021

47. Mattos A, Khalil NM, Mainardes RM. Development and validation of an HPLC method for the determination of fluorouracil in polymeric nanoparticles. Br J Pharm Sci. 2013;49:117-126. doi:10.1590/ S1984-82502013000100013

48. United States Pharmacopeial Convention. (1225) Validation of Compendial Procedures. United States Pharmacopeial Convention; 2019.

49. Zafar H, Mau M, Arshad S, Altaf H, Ma M, Rehman M. Simultaneous Quantification of 5-Fluorouracil and Leucovorin in Pharmaceutical Dosage Form and Human Spiked Plasma by Using RP- HPLC Method. J Chromatography Separation Tech. 2014;05.

50. Sanganal S, Kulkarni GB, Karegoudar TB. Development and validation of high performance liquid chromatographic analysis of residual N,N-Dimethylformamide in Spent Medium after Biodegradation by Paracoccus denitrificans SD1. ISRN Chromatography. 2013;20 13:401629. doi:10.1155/2013/401629

51. Chan CM, Frimberger AE, Moore AS. A literature review of reports of the stability and storage of common injectable chemotherapy agents used in veterinary patients. Vet Comp Oncol. 2017;15 (4):1124-1135. doi:10.1111/jedm.12046

52. Galanti L, Lebitasy MP, Hecq JD, Cadrobbi J, Vanbeckbergen D, Jamart J. Long-term stability of 5-Fluorouracil in $0.9 \%$ sodium chloride after freezing, microwave thawing, and refrigeration. Can J Hosp Pharm. 2009;62(1):34-38. doi:10.4212/cjhp.v62i1.115

53. Milano G, Etienne M-C, Cassuto-Viguier E, et al. Long-term stability of 5-fluorouracil and folinic acid admixtures. Eur J Cancer. 1993;29 (1):129-132. doi:10.1016/0959-8049(93)90590-C

54. Williams DA, Lokich J. A review of the stability and compatibility of antineoplastic drugs for multiple-drug infusions. Cancer Chemother Pharmacol. 1992;31(3):171-181. doi:10.1007/BF00685544

55. Ibrahim RA, Suhail FSA, Al-Hakeim HK. Stability of Anticancer Drug 5-Fluorouracil in Aqueous Solution: an Assessment of Kinetic Behavior. Nano Biomed Eng. 2018;10(3):224-234.

56. Charalambides D, Segal I. Colonic pH: a comparison between patients with colostomies due to trauma and colorectal cancer. $\mathrm{Am}$ J Gastroenterol. 1992;87(1):74-78.

57. Evans DF, Pye G, Bramley R, Clark AG, Dyson TJ, Hardcastle JD. Measurement of gastrointestinal $\mathrm{pH}$ profiles in normal ambulant human subjects. Gut. 1988;29(8):1035-1041.

58. McDougall CJ, Wong R, Scudera P, Lesser M, DeCosse JJ. Colonic mucosal pH in humans. Dig Dis Sci. 1993;38(3):542-545. doi:10. 1007/BF01316512

59. Pye G, Evans DF, Ledingham S, Hardcastle JD. Gastrointestinal intraluminal $\mathrm{pH}$ in normal subjects and those with colorectal adenoma or carcinoma. Gut. 1990;31(12):1355-1357. doi:10.1136/gut. 31.12.1355

60. Chinembiri TN, Gerber M, Du Plessis L, Du Preez J, Du Plessis J. Topical Delivery of 5-Fluorouracil from Pheroid ${ }^{\mathrm{TM}}$ formulations and the in vitro efficacy against human melanoma. AAPS PharmSciTech. 2015;16(6):1390-1399. doi:10.1208/s12249-015-0328-7

61. Vermaas M. Formulation of 5-Fluorouracil for Transdermal Delivery. Potchefstroom, North-West: School of Pharmacy, NorthWest University; 2010.

62. Shin MS, Hong JY, Park S. Gemcitabine release behavior of polyurethane matrixes designed for local anti-cancer drug delivery via stent. J Drug Deliv Sci Technol. 2012;22(4):301-306. doi:10.1016/ S1773-2247(12)50050-X

63. Bege N, Steinmüller SO, Kalinowski M, et al. Drug eluting stents based on Poly(ethylene carbonate): optimization of the stent coating process. Eur J Pharm Biopharmaceutics. 2012;80(3):562-570. doi:10.1016/j.ejpb.2011.12.006 
64. Mc Conville C, Major I, Friend DR, Clark MR, Woolfson AD, Malcolm RK. Development of polylactide and polyethylene vinyl acetate blends for the manufacture of vaginal rings. $J$ Biomed Mater Res B Appl Biomater. 2012;100B(4):891-895. doi:10.1002/jbm.b.31919

65. Wolinsky JB, Colson YL, Grinstaff MW. Local drug delivery strategies for cancer treatment: gels, nanoparticles, polymeric films, rods, and wafers. J Control Release. 2012;159(1):14-26. doi:10.1016/j. jconrel.2011.11.031

66. Jang SI, Lee DK. Stents with specialized functions: drug-eluting stents and stents with antireflux devices. Gastrointestinal Intervent. 2015;4(1):50-54. doi:10.1016/j.gii.2015.03.004

67. Kim DH, Jeong Y-I, Chung C-W, et al. Preclinical evaluation of sorafenib-eluting stent for suppression of human cholangiocarcinoma cells. Int J Nanomedicine. 2013;8:1697-1711. doi:10.2147/IJN.S43508

68. Zhao L, Gao Y, Gu G, et al. Rational design of drug-eluting stents via electrospray and in vivo evaluation of preventing oesophageal stricture. RSC Adv. 2014;4(32):16885-16892. doi:10.1039/C4RA01300J

69. KobryD J, Sowa S, Gasztych M, Musia BW. Influence of hydrophilic polymers on the factor in weibull equation applied to the release kinetics of a biologically active complex of aesculus hippocastanum. Int J Polym Sci. 2017;2017:1-8. doi:10.1155/2017/3486384
70. Smallwood IM. Methylene chloride. In: Smallwood IM, editor. Handbook of Organic Solvent Properties. Oxford: ButterworthHeinemann; 1996:137-139.

71. United States Pharmacopeial Convention. Residual Solvents; 2019. Available from: https://www.uspnf.com/sites/default/files/usp_pdf/ EN/USPNF/revisions/gc-467-residual-solvents-ira-20190927.pdf. Accessed January 30, 2020.

72. Harrell CR, Djonov V, Fellabaum C, Volarevic V. Risks of using sterilization by gamma radiation: the other side of the coin. Int J Med Sci. 2018;15(3):274-279. doi:10.7150/ijms.22644

73. ICH Harmonised Tripartite Guideline. Stability testing of new drug substances and products Q1A(R2). Available from: https:/www.ema. europa.eu/en/documents/scientific-guideline/ich-q-1-r2-stability-test ing-new-drug-substances-products-step-5_en.pdf. Accessed February 23, 2020.

74. Kamberi M, Rapoza R. Stability testing of drug eluting stents. J Drug Deliv Sci Technol. 2016;35:58-68. doi:10.1016/j.jddst.2016.05.006
Drug Design, Development and Therapy

\section{Publish your work in this journal}

Drug Design, Development and Therapy is an international, peerreviewed open-access journal that spans the spectrum of drug design and development through to clinical applications. Clinical outcomes, patient safety, and programs for the development and effective, safe, and sustained use of medicines are a feature of the journal, which has also

\section{Dovepress}

been accepted for indexing on PubMed Central. The manuscript management system is completely online and includes a very quick and fair peer-review system, which is all easy to use. Visit http://www. dovepress.com/testimonials.php to read real quotes from published authors. 